\title{
Climate change "conditionality": The case for bundling the fate of international-trade legal obligations and climate-change-relevant legal obligations
}

\author{
Eduardo Alvarez Armas
}

\begin{abstract}
This paper intends to make a contribution to the global debate on climate change mitigation by suggesting the transposition of a peculiar human-rights-enhancing notion (developed by the European Institutions over the past three decades) towards the intersection between international trade law and climate-change issues. The said notion, "conditionality", is a practice entails that the obligations assumed by the EU in the international cooperation and development agreements it signs with developing countries are conditional on those recipients' continuous and clear respect of basic human rights.

This paper's hypothesis is that if obligations in cooperation and development agreements can be made conditional on the respect by other parties of human rights, then obligations in international trade agreements can be made conditional on the respect by other parties of their respective climate-change obligations. In other words, "climate change conditionality" would mean that there would be no free-trade benefits without effective fulfillment of international climate-changerelated obligations.

The feasibility of this idea will be assessed via the textual analysis of the current wording and content of environmental / climate-change-related elements already present in a sample of relatively recent and / or upcoming Free Trade Agreements. This exercise intends to ascertain whether elements already present therein may be used to build climate change conditionality upon them.
\end{abstract}

\section{Keywords}

Climate change conditionality - International trade law - Human rights conditionality

\section{Introduction}

The following pages will introduce the contribution that international trade law may make to global decarbonization, as inspired by human-rights practices of the European Union. As disparate as these topics and realms may seem at first sight, there is a significant potential in transposing a peculiar human-rights-enhancing notion, developed by the European Institutions over the past three decades, towards the intersection between international trade law and climate-change. 
In a nutshell, the said notion, "conditionality", is a practice that involves linking the effective fulfilment of European cooperation and development engagements towards third parties, on the one hand, with the respect of basic human-rights by those third parties, on the other hand. In other words, conditionality entails that the obligations assumed by the European Union in the international cooperation and development agreements it signs with developing countries are conditional on those recipients' continuous and clear respect of basic human rights (Velluti, 2016, Hachez, 2015).

This paper's hypothesis is that if obligations in cooperation and development agreements can be made conditional on the respect by other parties of human rights, then obligations in international trade agreements can be made conditional on the respect by other parties of their respective climate-change obligations. In other words, international trade law may be used to help decarbonize the economy by bundling the fate of Free Trade Agreements - hereinafter FTAs - and international climate-change obligations: the breach of the latter would give rise to legal consequences under the dispute settlement mechanisms of the former (i.e, no free-trade-benefits without effective fulfillment of international climate-change-related obligations).

The feasibility of this idea will be assessed via the textual analysis of the current wording and content of environmental / climate-change-related elements already present in a sample of relatively recent and / or upcoming FTAs. This exercise intends to ascertain whether elements already present in FTAs may be used to build climate change conditionality upon them. However, as a complement to pure textual analysis, a brief reference will be made to similar academic endeavours by other authors, which have resorted to either resembling or alternative methodologies. Thus, the rather lengthy textual analysis (2) and the brief academic reference (3) will be completed by a synthesis (4) and some conclusions (5).

\section{Empirical assessment: "environmental" language and content of sample FTAs}

The first sub-section will be descriptive: a review of the relevant language and content of a selection of 14 FTAs. When analyzing their environmental and / or climate-change-relevant substantive content, and its potential articulation with dispute settlement mechanisms at least five different configurations can be identified therein. Let us assess them in sequence.

First configuration - Enforceability, but weak substantive content: The TPP and the ASEAN agreements with China and India

The first possible configuration to be found within the sample selected is embodied in three different agreements within the sample: i) the "Trans-Pacific Partnership" (TPP), a trade agreement originally signed by twelve Asia-Pacific nations on February the $4^{\text {th }} 2016$; ii) the 
"Framework Agreement on Comprehensive Economic Co-operation between the Association of South East Asian Nations and the People's Republic of China" (ASEAN-China Agreement), an international agreement which created a free trade area between the members of the ASEAN and China, and which entered into force on January the $1^{\text {st }} 2010$; and iii) the "Framework Agreement on Comprehensive Economic Cooperation Between the Republic of India and the Association of Southeast Asian Nations" (ASEAN-India Agreement); another international agreement which also created a free trade area between the members of the ASEAN and India, and which equally entered into force on January the $1^{\text {st }} 2010$.

The first agreement in the sample, the TPP is not yet in force, and its future has been called into question since the United States decided to withdraw from it in 2017 (CNN, 2017). Interestingly for this paper's purposes, the TPP contains a chapter specifically entitled "environment" (Chapter 20). This chapter envisages in Article 20.23 resort to Dispute Resolution if other means to solve controversies arising therefrom have failed. This includes, notably, resort to Consultations (Article 28.5) and possibly to the establishment of a Panel (Article 28.7.) Following Article 28.12, the function of a Panel "is to make an objective assessment of the matter before it, [...] and to make the findings, determinations and recommendations as are called for in its terms of reference and necessary for the resolution of the dispute." The Panel will prepare an initial report (Article 28.17), and, where appropriate, a final report (Article 28.18), whose implementation will be assessed (Article 28.19). In the event of non-implementation, the non-complying party may either need to provide compensation, or may either face a suspension of the benefits granted under the TPP (or, under certain conditions, may have to pay a monetary assessment) (Article 28.20). This regime would, in principle, provide significant chances of international enforceability to the obligations contained in Chapter 20 of the TPP (Hillman, 2016). However, while the said chapter does contain an article entitled "Transition to a Low Emissions and Resilient Economy" (Article 20.15), whose content is relevant for the purposes of this paper, the article's language is very weak, making it hard to substantiate any solid claim:

"1. The Parties acknowledge that transition to a low emissions economy requires collective action.

2. The Parties recognise that each Party's actions to transition to a low emissions economy should reflect domestic circumstances and capabilities and, consistent with Article 20.12 (Cooperation Frameworks), Parties shall cooperate to address matters of joint or common interest. [...] Further, the Parties shall, as appropriate, engage in cooperative and capacity-building activities related to transitioning to a low emissions economy". [Emphasis added]

Such weak substantive content makes irrelevant the fact that Article 20.15 comes within the scope of the Dispute Settlement scheme provided for in the Treaty.

A similar, albeit slightly different description can be made of the ASEAN-China and the ASEANIndia Agreements, the second and third agreements mentioned above. Since their structure and content are almost identical, they may be dealt with simultaneously: while the respective contents 
of these agreements are meant to be enforceable under additional dispute-settlement agreements between the parties, their actual environmentally-relevant contents are restrained to simply providing for cooperation on environmental issues, as an area of "economic co-operation". This renders the availability of enforcement mechanisms and redress, again, irrelevant.

\section{Second configuration - Ambiguous substantive content, and non-enforceability: Selected EU FTAs}

The second possible configuration that may be found within the sample of treaties is embodied in the following five EU-promoted trade agreements: the "Free trade Agreement between the European Union and its Member States, of the one part, and the Republic of Korea, of the other part" (EU-South Korea FTA; in force as of December the 13 ${ }^{\text {th }} 2015$ ); the "Trade Agreement between the European Union and its Member States, of the one part, and Colombia and Peru, of the other part" (EU- Colombia-Peru TA; provisionally applied as of March the $1^{\text {st }} 2013$ in respect of Peru, and as of August the $1^{\text {st }} 2013$ in respect of Colombia); the "Association Agreement between the European Union and its Member States, of the one part, and Ukraine, of the other part" (in force as of September the 1 ${ }^{\text {st } 2017) ; ~ t h e ~ " C o m p r e h e n s i v e ~ E c o n o m i c ~ a n d ~ T r a d e ~ A g r e e m e n t ~}$ (CETA) between Canada, of the one part, and the European Union and its Member States, of the other part" (CETA; Not yet in force, signed on October the 30 ${ }^{\text {th }} 2016$ ); and the "Japan-EU Economic Partnership Agreement" (JEEPA; not yet signed). Overall, the environmental language and content of the post-2008-financial-crisis EU FTAs seem to be relatively stable (with the notable exception, as it will be seen below, of the EU-Colombia-Peru TA), and, therefore, they will be assessed simultaneously. In terms of substantive content, generally speaking, these agreements tend to contain a chapter on "Trade and sustainable development" or "Trade and environment", within which an article on "Multilateral environmental agreements" may be found. The content of the said article has a constant basis, upon which other elements are pinned. The said basis is constituted by the following language:

"1. The Parties recognise the value of international environmental governance and agreements as a response of the international community to global or regional environmental problems.

2. The Parties reaffirm their commitments to the effective implementation in their laws and practices of the multilateral environmental agreements to which they are party."

This common basis is sometimes accompanied by further paragraphs which, despite depicting progressive intentions, are unable to lead to ambitious environmental outcomes. As brief examples, in the Agreements with South Korea and Japan, the parties mention the United Nations Framework Convention on Climate Change and the Kyoto Protocol (in the case of the JEEPA, the Paris Agreement), but only to state that they "reaffirm their commitment to reaching [the Agreements'] ultimate objective". The Agreement with Ukraine establishes further means through which the parties "shall cooperate"; as does CETA, which adds that the parties "commit to consult" and "exchang[e] information". Equally, the first paragraph above is sometimes accompanied by additional elements which remain within the same vague narrative (the parties "commit to consulting and cooperating", "stress the need to enhance", etc.) 
However, beyond these considerations, which would tend to sustain the conclusion that the substantive content of the concerned Agreements is purely and simply weak, a qualification may be made: the second paragraph is ambiguous in its content. The paragraph begins with a typically "weak" wording ("The Parties reaffirm their commitments") but, instead of referring to weak policy objectives, it refers to the "effective implementation in their laws and practices [...] of the multilateral environmental agreements to which they are party." It, therefore, could be argued that, despite its beginning, the paragraph actually links, in a solid manner, the trade agreement to the relevant multilateral environmental agreements (any relevant agreement to which they are party, without limitation): in other words, it could be argued that a lack of "effective implementation in their laws and practices" of the relevant environmental agreements entails a breach of paragraph 2.

This potential interpretation is further reinforced by the specific wording of the relevant provisions of the EU-Colombia-Peru FTA. The second, third and fourth paragraphs of Article 270 ("Multilateral Environmental Standards and Agreements"), included in Title IX ("Trade and sustainable development") of the said FTA, read as follows:

"2. The Parties reaffirm their commitment to effectively implement in their laws and practices the following multilateral environmental agreements: the Montreal Protocol on Substances that Deplete the Ozone Layer adopted on 16 September of 1987, the Basel Convention on the Control of Transboundary Movements of Hazardous Wastes and their Disposal adopted on 22 March 1989, the Stockholm Convention on Persistent Organic Pollutants adopted on 22 May 2001, the Convention on International Trade in Endangered Species of Wild Fauna and Flora signed on 3 March 1973 (hereinafter referred to as "CITES"), the CBD, the Cartagena Protocol on Biosafety to the CBD adopted on 29 January 2000, the Kyoto Protocol to the United Nations Framework Convention on Climate Change adopted on 11 December 1997 (hereinafter referred to as "Kyoto Protocol") and the Rotterdam Convention on the Prior Informed Consent Procedure for Certain Hazardous Chemicals and Pesticides in International Trade adopted on 10 September 1998.

3. The Trade Committee may recommend the extension of the application of paragraph 2 to other multilateral environmental agreements [...].

4. Nothing in this Agreement shall limit the right of a Party to adopt or maintain measures to implement the agreements referred to in paragraph 2. [...]"[Emphasis added, original footnotes omitted]

Paragraph 2 of the article contains a list with a limited number of precisely identified agreements. At its present state, this provision does not seem very prone to providing coverage to climatechange instruments (Only one of the instruments listed in paragraph 2, the Kyoto Protocol, may be characterized as a climate-change instrument. Beyond this, in the EU-Colombia-Peru FTA, Climate change agreements are the object of a separate, notably weak provision, Article 275.) Notwithstanding this fact, it may be argued that it does not contain vague policy objectives and statements, but clear, precise 
and solid obligations. If this is the case, the above-referred parallel provisions in other EU FTAs may be interpreted accordingly, as being open-ended clauses (hence, not restrained to a limited list of treaties), containing the same kind of clear, precise and solid obligations.

However, in order for this ambiguous possibility to have any practical impact, the said provisions would need to be enforceable under the relevant "Dispute Settlement" provisions in the respective EU FTAs, which does not seem to be the case. While, in most cases, the dispute settlement chapters of the selected FTAs are assorted with provisions which state that their scope is general and covers the entirety of the said agreements, these provisions operate only "unless otherwise provided". The environmentally-relevant chapters, therefore, exclude resort to dispute settlement under various formulations. In general, they only provide for soft and conciliatory mechanisms, such as "Government consultations", or the establishment of "panels" or "groups" of experts, who draft "initial" and, "final" reports, on how to solve issues. The parties then "shall take into account the final report", or "inform the [relevant entity] of its intentions as regards the recommendations", or "discuss actions or measures to resolve the matter in question, taking into account the [...] report and suggestions." The parties' courses of action are often "monitor[ed]", but no consequence is provided for.

\section{Third configuration - Solid substantive content, but non-enforceability: The EU- Singapore FTA}

A third possible configuration is reflected in the text of the "Free Trade Agreement between the European Union and the Republic of Singapore" (EU-Singapore FTA; not yet signed.) Chapter thirteen ("Trade and sustainable development") contains in Section C ("Trade and Sustainable Development - Environmental Aspects") an Article on "Multilateral Environmental Standards and Agreements" (Article 13.6) which bears a structure which greatly resembles the one described in the analysis of the previous configuration (i.e., "ambiguous substantive content but weak enforceability"). However, in this occasion there is no possible ambiguity:

"2. The Parties shall effectively implement in their respective laws, regulations or other measures and practices in their territories, the multilateral environmental agreements to which they are party." [Emphasis added; original footnote omitted]

The wording of the second paragraph of this Article is clearly assertive, without any sort of resort to the typical vague language found in weak policy statements. It can hardly be argued that it does not contain clear, precise and solid obligations. A priori, its only fault, for the purposes of this paper, is that it clearly does not cover climate-change obligations, for climate change is the object of the third paragraph of the Article, which is undoubtedly weak in its content:

"3. The Parties reaffirm their commitment to reaching the ultimate objective of the UN Framework Convention on Climate Change (hereinafter referred to as "UNFCCC"), and of its Kyoto Protocol in a manner consistent with the principles and provisions of the UNFCCC. They commit to work together to strengthen the multilateral, rules-based 
regime under the UNFCCC building on the UNFCCC's agreed decisions, and to support efforts to develop a post-2020 international climate change agreement under the UNFCCC applicable to all parties." [Emphasis added]

In any case, again, as was the case in the second model, for the second paragraph of this provision to have any practical impact, it would need to be enforceable under the relevant "Dispute Settlement" chapter. And, again, this does not seem to be the case.

\section{Fourth configuration - Enforceability, but ambiguous substantive content: The TTIP}

The "Transatlantic Trade Investment and Partnership" (TTIP), that the European Union and the United States began negotiating between the $7^{\text {th }}$ and the $12^{\text {th }}$ of July 2013, is at the roots of the fourth configuration detected in the sample of Treaties. Notwithstanding the fact that a significant amount of uncertainty swirls around its future, draft-documents on this envisaged agreement, reflecting different stages in the negotiations, will serve as the basis for the analysis. The first of such documents is the EU's "initial proposal for legal text on "Trade and Sustainable Development" drafted to serve during the negotiating round with the United States that took place between the $19^{\text {th }}$ and the $23^{\text {rd }}$ October 2015 (EU Commission, 2015). Within "Section III" (named "Trade and Sustainable Development - Environmental aspects"), Article 10 ("Multilateral environmental governance and rules") contains the following language:

"1. The Parties recognise the value of global environmental governance and rules, including Multilateral Environmental Agreements, to tackle environmental challenges of common concern and stress the need to enhance the mutual supportiveness between trade and environment policies, rules and measures.

2. Each Party reaffirms its commitment to effectively implement in its domestic laws and practices the Multilateral Environmental Agreements to which it is a party.

3. The Parties should continue to strive towards further ratification of Multilateral Environmental Agreements and cooperate in this regard, including through exchanging information on advancement and supporting each other's full participation in, or membership to, multilateral environmental agreements, international bodies, and processes.

4. The Parties commit to consult and cooperate with each other as appropriate in Multilateral Environmental Agreements and other global environmental fora, in particular trade-related environmental issues.

5. The Parties acknowledge that nothing in the Agreement should prevent either Party from adopting or maintaining measures to implement the Multilateral Environmental Agreements to which it is a party, [...]." [Emphasis added; original footnotes omitted] 
In general terms, the wording of Article 10 roughly corresponds with that of equivalent substantive provisions in the EU FTAs that were classified as having an "ambiguous substantive content" but lacking enforceability (i.e., the second configuration above). However, what distinguishes this early TTIP document from the above-commented EU FTAs is precisely the fact that, following an EU's "initial proposal for legal text on "Dispute Settlement (Government to Government)" the TTIP's relevant provisions would be enforceable. Article 2 ("Scope of application") in Section 1 ("Objective and Scope") establishes that the dispute settlement chapter applies to "any dispute concerning the interpretation and application of the provisions of this Agreement, except as otherwise provided."

This assessment, made on the basis of a rather early-stage document, may be altered if the content of a second document, stemming from a later round of the negotiations (11-15 July 2016), gets to be inserted into the relevant chapter of the TTIP. The EU's "initial proposal for a legal text on climate which would be included [sic] to the "Trade and Sustainable Development" chapter in TTIP" (EU Commission, 2016) contains lengthy language on "Trade favouring low-emission and climate-resilient development" and "Protection of the Ozone Layer and Measures Related to Hydrofluorocarbons". For the sake of brevity (especially taking into account the above-referred uncertainty surrounding the negotiations) suffice it to say that most of the content of the draft provisions can be easily qualified as "weak", for it reflects the same kind of language as other provisions transcribed in previous pages. However, each of the two unnumbered draft provisions features a paragraph bearing more solid content:

"4. [...] the Parties shall: [...] b) effectively implement the WTO Environmental Goods Agreement (EGA) and in this context cooperate to reduce or, as appropriate, eliminate non-tariff barriers related to environmental goods and services;" [Emphasis added]

"2. [...] each Party shall take measures to control the production and consumption of, and trade in, substances within the scope of the Montreal Protocol on Substances that Deplete the Ozone Layer, including any future amendments thereto." [Emphasis added]

Nevertheless, as none of these paragraphs with "solid" content refers to any of the core climatechange agreements, they may only be collaterally relevant, if anything, for the purposes of this section.

The potential insertion of this language into the TTIP would make it unlikely that climate change be covered by the above referred Article 10. This would mutate this fourth configuration, thus making it partially resembling to the first configuration described above (namely, "strong enforceability, but weak content.") This fourth configuration would, nevertheless, remain a distinct one, for despite the provision's general weakness, it does contain solid obligations as regards collaterally-relevant agreements, which is not the case regarding its counterpart in the TPP.

In any case, irrespective of the "ambiguity" in Article 10, and irrespective of the potential impact of the insertion of the unnumbered provisions just discussed, a major hindrance to the 
enforceability dimension of the TTIP, which is also shared by the TPP, would always remain: Putting aside the actual architecture and specific features that a final TTIP may possibly come to display, what is really fundamental is the fact that the United States has not ratified the Kyoto Protocol and is possibly going to withdraw from the Paris Agreement on Climate Change (New York Times, 2017.) Consequently, there would be no relevant climate-change obligation that could potentially come to be enforced via this trade agreement.

As interesting for this papers' purposes as they are, these developments on the TTIP negotiations, as it has been already highlighted, do not provide a sufficient degree of certainty. Therefore, discussion will stop at this point, and switch to the last treaty configuration detected in the sample.

\section{Fifth configuration - Solid substantive content, and enforceability, but restrictive scope: Selected US FTAs}

The fifth and final configuration found in the sample of treaties chosen can be found in three US international economic agreements: the "Free Trade Agreement between the United States of America and the Republic of Korea" (KORUS; entered into force on March the 15 ${ }^{\text {th }}$ 2012), the "United States-Peru Trade Promotion Agreement" (US-Peru TPA; entered into force on February the $1^{\text {st }} 2009$ ), and the "United States-Colombia Trade Promotion Agreement" (US-Colombia TPA; entered into force on May the $15^{\text {th }}$ 2012.) As it was the case with the EU FTAs, these agreements bear a great resemblance in their wordings, for the purposes of this paper. Therefore, the following commentary will focus on the US-Peru TPA, but all observations are applicable, mutatis mutandis, to the other two legal instruments. Chapter Eighteen of the US-Peru TPA ("Environment") contains an article on "Environmental Agreements" (Article 18.2) which reads as follows:

"A Party shall adopt, maintain, and implement laws, regulations, and all other measures to fulfill its obligations under the multilateral environmental agreements listed in Annex 18.2 ("covered agreements")." [Emphasis added]

The restrictive list of "covered agreements" referred to (which is identical in all three treaties) is composed of seven international agreements, amongst which the "Convention on International Trade in Endangered Species of Wild Fauna and Flora" (CITES), the "Montreal Protocol on Substances that Deplete the Ozone Layer", and the "Protocol of 1978 Relating to the International Convention for the Prevention of Pollution from Ships, 1973" (MARPOL), as well as other less significant instruments. The relationship between, on the one hand, the US-Peru TPA, and any of the targeted multilateral environmental agreements is further shaped by Article 18.13 (“Relationship to Environmental Agreements"):

"1. The Parties recognize that multilateral environmental agreements to which they are all party, play an important role globally and domestically in protecting the environment and that their respective implementation of these agreements is critical to achieving the 
environmental objectives thereof. The Parties further recognize that this Chapter and the ECA can contribute to realizing the goals of those agreements. [...]

2. To this end, the Parties shall consult, as appropriate, with respect to negotiations on environmental issues of mutual interest.

3. Each Party recognizes the importance to it of the multilateral environmental agreements to which it is a party.

4. In the event of any inconsistency between a Party's obligations under this Agreement and a covered agreement, the Party shall seek to balance its obligations under both agreements, but this shall not preclude the Party from taking a particular measure to comply with its obligations under the covered agreement, [...]." [Emphasis added]

Putting aside the fact that Article 18.13 resorts to weak and vague language (possibly in order not to force the preeminence of environmental values over economic ones), the main article discussed, namely Article 18.2, is precise, unconditional and assertive, and neatly establishes clear obligations which, in this case, are actually enforceable under the relevant dispute settlement provisions. In this sense, Article 18.12 ("Environmental Consultations and Panel Procedure") establishes, amongst other aspects, in paragraph 6, that a complaining party may "as provided in Chapter Twenty-One (Dispute Settlement), thereafter have recourse to the other provisions of that Chapter". Specifically, by establishing how "a panel convened under [the] Dispute Settlement [chapter]" is meant to make its "findings", paragraph 8 of the same article provides guidance as regards the operation of the dispute settlement provisions in respect of Article 18.2 ("Environmental Agreements"). Within the provisions on dispute settlement of the US-Peru TPA, Article 21.16 ("Non-Implementation - Suspension of Benefits") establishes that an infringing party may have to provide compensation or may, under certain conditions, see her rights under the Treaty suspended.

However, despite the Agreement's clear enforceability (and solid substantive content), there are, at least, two restrictions in the scope of the relevant provisions, which render this fifth Treaty configuration unfit for the purposes of this paper. The first one arises from the fact that, as already mentioned, the Treaties feature a restrictive list of "covered agreements" which does not contain any climate-change-relevant international instrument. The second one, which is just equally important, arises from a footnote placed immediately after the title of the "Environmental Agreements" provision in each of the Treaties. The one in Article 18.2 of the US-Peru TPA reads as follows:

"1 To establish a violation of Article 18.2 a Party must demonstrate that the other Party has failed to adopt, maintain, or implement laws, regulations, or other measures to fulfill an obligation under a covered agreement in a manner affecting trade or investment between the Parties." [Emphasis added]

This entails that only a specific kind of breach of the "covered agreements" may potentially lead to legal consequences under the dispute settlement provisions of the relevant Treaties. As it may be understood, therefore, the potential of this fifth Treaty configuration is severely hindered. While 
it is still too early to say, it is likely that the potential recast of the North American Free Trade Agreement (NAFTA), whose renegotiation rounds begun during Summer 2017, may end up belonging to this category. Following a "Summary of Objectives for the NAFTA Renegotiation" released by the office of the United Stated Trade Representative on July the $17^{\text {th }} 2017$, the United States intend to insert provisions on environmental issues into the text of the NAFTA (USTR, 2017.) Specifically, the very little guidance provided by the said document possibly hints at the replication of the structural configuration described above, including its restrain to a limited list of "covered agreements".

Having concluded the description of the fifth configuration, let us briefly consider other similar academic accounts which have resorted to other methodologies.

\section{Other academic accounts}

The textual analysis in previous pages needs to be complemented by a brief reference to other academic assessments, which have been performed along similar lines (resembling focuses, either under different or slightly varying methodologies) in recent years. These studies provide a wider context to the referred textual analysis and further enlighten the potential contribution of FTAs to international environmental and climate change-related.

A first account to be mentioned, was performed by S. Jinnah \& E. Morgera in 2013. It comprised a sophisticated analysis, based on coding, of Environmental provisions in American and EU Free Trade Agreements (Jinnah and Morgera, 2013). This interesting and timely work does not focus, however, on climate-change-relevant provisions, which are only very briefly and generically addressed. Nevertheless, this piece is extremely valuable, inasmuch as it shows (although not explicitly stated) the potential that future climate-relevant provisions could come to bear, if, in policy terms, an approach similar to the one taken in respect of generic environmental provisions was adopted.

A second account, which runs along similar lines, and deserves being highlighted is the very recent work performed by J. F. Morin \& R. Gauthier Nadeau on what they label as "environmental gems" in trade agreements: in their opinion several very innovative environmentally-relevant provisions found in a rather limited number of trade agreements are good examples of "best practices" that should actually be amplified and replicated in future agreements. Most of these "legal one-hit-wonders" are not directly climate-change relevant (there is only a brief reference to "two Stabilisation and Association Agreements of the European Union [calling] for the ratification of the Kyoto Protocol on Climate Change"), yet, again, they point to the huge potential that a similar approach in climate-change terms would have (Morin J F and Gauthier Nadeau R, 2017).

Finally, N. A. J. Croquet has performed an in-depth analysis of "The climate-change norms under the EUKorea Free Trade Agreement" which rightly points to the need of assessing, in every case, what is the actual value of the climate-change relevant provisions that may be found in trade agreements (Croquet, 2015). When discussing this point as regards the EU-Korea FTA, Croquet, following assessments by A. Boyle, and by K. Abbott and D. Snidal, places this question within the academic soft law-hard law continuum. It is under these coordinates that he asserts, following the referred authors, that "given that the EU-Korea 
FTA constitutes hard law vis-à-vis the contracting parties", climate change provisions are to be considered from the standpoint of two additional elements: "their degree of precision" and "their enforcement/dispute settlement mechanism". Consequently, Croquet goes on to consider: i) that what we have labelled as "ambiguous provisions" in previous pages are actually "renvoi clauses", i.e. "confirmatory clauses that urge the Contracting parties to live up to their pre-existing climate change treaty commitments"; ii) that in the EU-Korea FTA case the renvoi clause is unambiguous and reflects an unequivocal obligation to "effectively implement" previously assumed climate change-relevant obligations; iii) "that these preexisting treaty commitments now fall under the Chapter 13 dispute settlement mechanism." As relevant and enlightening as this account is, it is not possible to fully subscribe it, nevertheless: while it may be possible to agree with ii), as Croquet quotes documentation by the "WTO Committee on Regional Trade Agreements", it is not possible to fully agree with iii). What Croquet labels as "dispute settlement" is a set of provisions within Chapter 13 ("Trade and sustainable development") which is independent from the "Dispute settlement" Chapter (Chapter 14) and which, ultimately, is not accompanied by any sort of remedy.

In the light of all of these considerations, let us synthetize the findings of previous pages.

\section{Synthesis: The case for bundling Trade and Environmental agreements}

Textual analysis shows that, as the law stands nowadays, there are, at least, four sorts of obstacles to the hypothesis presented in this paper:

1) Weak and/or vague language of the relevant "primary" obligation (example: the TPP): whenever a given climate-change relevant provision is covered by the dispute settlement mechanism, the actual content of the relevant obligation is weak, and thus rather useless.

2) Lack of coverage by the relevant dispute-settlement provisions (example: the EU-Singapore FTA): reverse problem; while the content / language of the relevant obligations is strong, the provision is not covered by the dispute settlement mechanism.

3) Severe limitations in the scope of the relevant provisions (example: the KORUS): whenever both the content / language of the primary obligations is unequivocal and the enforceability dimension thereof is strong, the relevant provision only covers a selected number of environmental agreements and / or is only triggered under certain narrow conditions.

4) Lack of environmental commitment by at least one of the parties (example: the TTIP): No bundled climate-change enforcement would be possible because the relevant party has not ratified any meaningful international climate-change obligation.

Depending on the reading that may be made of the provisions labeled above as "ambiguous", a fifth point could be added: If the said provisions are to be considered as actually "ambiguous", an additional difficulty would arise from the fact that the precise content of the relevant obligation is not, in principle, easy to ascertain due to the combination of seemingly "weak" and "solid" 
elements in its wording. If, however, the said provisions are to be understood, following Croquet's analysis, as being actually clear, no addition needs to be made.

Notwithstanding all of these facts, in normative terms (de lege ferenda), an effective way for the European Union to move forward regarding the enforcement of international climate-changemitigation obligations would be to bundle the fate of climate-change-relevant obligations with that of trade agreements. Since the relevant elements for "bundling" are already disseminated in various FTAs (some feature solid climate-change-linkage language, others feature coverage by the relevant dispute-settlement mechanism), law-makers would need to simultaneously include both sorts of elements in future FTAs to obtain the desired result:

1) In substantive terms, possibly the clearest wording found in the analyzed agreements is the one featured in Article 13.6 of the EU-Singapore FTA:

"2. The Parties shall effectively implement in their respective laws, regulations or other measures and practices in their territories, the multilateral environmental agreements to which they are party." [Emphasis added; original footnote omitted]

It is not a closed or limited list of agreements, but a general clause, and leaves no doubt regarding the kind and extent of obligation being assumed.

2) In enforceability terms, it will suffice to follow the example of the TPP and the US FTAs: in other words, the relevant provision needs to be covered by the Dispute Settlement Chapter of the relevant agreement, which needs to ultimately provide access to remedies such as compensation and suspension of benefits in case of "non-implementation" of panel reports.

\section{Conclusions}

International trade law may indeed make a substantial contribution to global decarbonization if "climate change conditionality" becomes an established practice. The textual analysis performed in this paper has showed that there is an interesting potential in this sense, and it would only require using a correct combination of already-existing provisions and language when drafting future treaties and agreements, and amending past ones.

Interestingly, a "partially progressive" trend in environmental terms is possibly starting: while CETA and JEEPA face, cumulatively, ambiguous content and un-enforceability, the EUSingapore FTA only suffers from un-enforceability, but has clearly solid content. Climate change conditionality could perfectly fit into this trend, provided that political will actually concurred.

Therefore, in a nutshell, the means to bundle the fate of international trade benefits to effective compliance with climate change obligations are available. The European Union, moreover, is placed in a privileged position to act in this sense, as it did in the past with human-rights conditionality. Again, it would only take political will. 


\section{References}

CNN (2017) TPP unravels: Where the 11 other countries go from here. http://edition.cnn.com/2017/01/24/asia/tpp-other-11-countries-what-next/index.html $\quad$ (Last accessed 15 Aug 2017)

Croquet, N A J (2015) The climate-change norms under the EU-Korea Free Trade Agreement: between soft and hard law. In Wouters J, Marx A, Geraerts D, Natens B (ed.), Global Governance through Trade EU Policies and Approaches, Leuven Global Governance series, Edward Elgar Publishing, Cheltenham, pp. 124-157.

EU Commission (2015) EU textual proposal - Trade and Sustainable Development - TTIP Negotiations. http://trade.ec.europa.eu/doclib/docs/2015/november/tradoc 153923.pdf (Last accessed 22 Aug 2017)

EU Commission (2016) European Union's initial proposal for a legal text on climate

- TTIP Negotiations. http://trade.ec.europa.eu/doclib/docs/2016/july/tradoc 154800.pdf (Last accessed 22 Aug 2017)

Hachez N (2015) 'Essential Elements' clauses in EU Trade Agreements Making Trade Work in a Way that Helps Human Rights? Leuven Centre for Global Governance Studies, Working Paper 158:1-24

Hillman J (2016) Dispute Settlement Mechanism. In Cimino-Isaacs C, Schoot JJ (eds.), TransPacific Partnership: An Assessment. Peterson Institute for International Economics, Washington D.C.

Jinnah S, Morgera E (2013) Environmental provisions in American and EU Free Trade Agreements: A Preliminary Comparison and Research Agenda, RECIEL 22(13):324-339

Morin J F, Gauthier Nadeau R (2017) Environmental Gems in Trade Agreements - Little-known Clauses for Progressive Trade Agreements, CIGI Papers 148:1-8

New York Times (2017) Trump Will Withdraw U.S. From Paris Climate Agreement, (https://www.nytimes.com/2017/06/01/climate/trump-paris-climate-agreement.html?mcubz=1

(Last accessed 22 Aug 2017)

USTR (2017) Summary of Objectives for the NAFTA Renegotiation. https://ustr.gov/sites/default/files/files/Press/Releases/NAFTAObjectives.pdf (Last accessed 30 Aug 2017)

Velluti S (2016) The Promotion and Integration of Human Rights in EU External Trade Relations. Utrecht Journal of International and European Law 32(83):41-68 


\section{Author's biography}

Doctor Eduardo Alvarez Armas obtained his "Licenciatura en Derecho" (LL.B) Summa Cum Laude at the Universidad de La Laguna (Tenerife) in 2006. Upon graduation, he began working for J \& A Garrigues, one of Spain's leading law firms, in their civil and commercial litigation department. In 2008 he moved to Belgium where he received a Masters in European Law at the College of Europe (Bruges - 2009) and a Masters in International Law at the Université catholique de Louvain (2010 - Summa Cum Laude). Between 2010 and 2015 he worked a Research fellow in legal sciences for the Belgian National Fund for Scientific Research (FNRS), teaching and researching at the Université catholique de Louvain on private international law, international environmental law, global governance and the law of the European Union. After obtaining an LL.M in American Law (Honours) at Stanford Law School in 2016, he defended his PhD dissertation in 2017 (Double PhD diploma, Université catholique de Louvain and Universidad de Granada - Summa Cum Laude). He is currently a Research Associate at Queen Mary University of London. 